\title{
ПРЕИМУЩЕСТВА И НЕДОСТАТКИ КОЭФФИЦИЕНТНОГО АНАЛИЗА
}

\author{
(c) 2020 Петров Александр Михайлович \\ доктор экономических наук, профессор Департамента учета, анализа и аудита \\ Финансовый университет при Правительстве Российской Федерации, Россия, Москва \\ Email:palmi@inbox.ru
}

На сегодняшний день весомой проблемой как для бюджетных организаций, так и для коммерческих организаций является выполнение обязательств перед партнерами. Для оценки финансового состояния контрагентов может помочь коэффициентный анализ финансовой отчетности. Актуальность данной статьи обуславливается тем, что в последние годы исследований, научных и практических трудов по данной проблеме сравнительно немного, несмотря на серьезность этого вопроса.

Ключевые слова: бухгалтерский учет, отчетность, коэффициентный анализ, автоматизация

Анализ финансовых показателей является одним из наиболее популярных методов анализа для компаний, особенно для небольших компаний. Коэффициентный анализ предоставляет информацию для сравнения предприятий в одной отрасли, сопоставления результатов деятельности предприятия со средними значениями по отрасли в целом, а также помогает отслеживать тенденции внутри компании во временном интервале.

Используя набор финансовых и операционных данных от компании или отрасли, он обеспечивает основу для сравнения. Наиболее часто использующиеся коэффициенты можно разбить на следующие категории:

- Коэффициенты ликвидности оценивают, насколько легко фирма может выполнить свои обязательства.

- Коэффициенты рентабельности показывают прибыльность деятельности компании.

- Коэффициенты управления активами служат мерой того, насколько эффективно компания использует свои активы.

- Коэффициенты управления долгом отражают финансовые рычаги и то, насколько эффективно компания может покрывать долги.

- Коэффициенты рыночной активности помогают сопоставить рыночную цену акции с ее учетной ценой и доходностью.

Может возникнуть вопрос, зачем необходим коэффициентный анализ, если есть финансовая отчетность, ознакомившись с которой можно сделать все необходимые выводы?

Во-первых, анализ значительно упрощает понимание финансовой отчетности. В настоящее время основными формами финансовой отчетности в России являются: Баланс, Отчет о финансовых результатах, Отчет о движении денежных средств.

Бухгалтерский баланс предприятия дает представление о величине, составе и структуре имущества предприятия, о направленности инвестиций за счет средств, используемых предприятием, а также за счет каких источников этих средств осуществлены инвестиции.

Отчет о финансовых результатах содержит информацию о деятельности предприятия по достижению своей первоочередной цели - получению прибыли, на основании которой возможна оценка и анализ эффективности деятельности предприятия.

Отчет о движении денежных средств отражает все денежные поступления предприятия и раскрывает их расходование в течение отчетного периода. Таким образом, данная форма позволит уточнить как источники формирования средств предприятия, так и источники изменений в его имуществе.

Для того, чтобы уметь «читать» информацию, содержащуюся в этих отчетах необходимо иметь экономическое или бухгалтерское образование. Это является значительным препятствием для руководителей в их способности делать верные выводы и принимать правильные решения. Сравнение же простых коэффициентов позволяет незамедлительно определить слабые и сильные стороны компании.

Во-вторых, с помощью коэффициентного анализа становится возможным сравнивать предприятия, отличающиеся по размерам. Сложно сравнивать чистую прибыль двух компаний, когда одна компания в три раза больше 
другой. Наши ожидания очевидны. Более крупная компания будет иметь большую чистую прибыль, но значит ли это, что компания - лучший выбор для инвестиций? С использованием коэффициентов, например, коэффициента маржи чистой прибыли, сравнение будет корректным; выводы, сделанные по итогам, будут обоснованными.

B-третьих, коэффициентный анализ финансовых показателей помогает в планировании и составлении стратегии развития бизнеса. Наблюдая тенденции по различным показателям, квартал за кварталом, руководство компании может принять своевременные решения для исправления складывающейся неблагоприятно ситуации. А сравнивая результаты, полученные в ходе анализа, своего предприятия с другими, руководство может определить слабые стороны, мешающие развитию бизнеса.

Однако следует помнить, что, несмотря на полезность, у коэффициентного анализа есть свои недостатки.

Первый из них это полная зависимость результатов анализа от информации, содержащейся в финансовой отчетности. Таким образом, если данные в финансовых отчетах искажены или допущена ошибка, результаты коэффициентного анализа будут некорректными.

Второй недостаток - сравнение показателей с данными других фирм может не соответствовать действительности. Несмотря на то, что существуют общепринятые принципы бухгалтерского учета для составления финансовой отчетности, различные показатели могут использоваться для вычисления коэффициентов. Например, для расчета оборачиваемости запасов одно предприятие может использовать себестоимость реализованной продукции в числителе, а другое, возможно, будет использовать выручку от продаж. Коэффициенты получатся разные. Важно помнить, что прежде, чем приступать к сравнению результатов, необходимо тщательно проверить соответствие используемых данных.
Третьим недостатком является тот факт, что существуют различные операционные методики ведения бизнеса. Это может привести к тому, что сравнение финансовых показателей окажется неуместным. Например, одна компания, может арендовать большую часть своих активов, в то время как другая может владеть ими. В этом случае, некоторые коэффициенты, такие как отношение суммарных обязательств к суммарным активам, коэффициент покрытия постоянных расходов, оборачиваемость активов и рентабельность активов будут несопоставимы.

Четвертый минус коэффициентного анализа заключается в том, что он не учитывает показатель инфляции. Например, оборачиваемость запасов может ухудшаться в течение трехлетнего периода; проблема может быть не в физическом увеличении запасов, а в существенном увеличении стоимости товара. Также увеличение рентабельности активов может не означать, что компании работает более эффективно; это может отражать тот факт, что продажи резко увеличились вследствие увеличения цены, а не объема, и что основные средства, которые показаны в финансовой отчетности по балансовой стоимости, остались неизменными.

Пятый недостаток коэффициентного анализа в том, что наиболее эффективен он будет в условиях, когда ассортимент компании невелик. Чем обширнее направления деятельности компании, тем сложнее провести качественный коэффициентный анализ.

В заключении заметим, что существует множество инструментов для повышения эффективности работы предприятия. Коэффициентный анализ является одним из них. Но, как и у каждого метода у него есть свои достоинства и недостатки. Было бы неверно составить свое мнение о деятельности компании, опираясь только на коэффициентный анализ. Однако, зная об определенных недостатках данного метода и учитывая их, руководство может принять своевременное решение для более детального анализа слабых сторон своей компании.

\section{Библиографический список}

1. Шеремет А.Д., Негашев Е.В. Методика финансового анализа деятельности коммерческих организаций. Учебник: 2-е изд., перераб. И доп.-М.: ИНФА-М, 2008.

2. Волнин В.А., Коэффициентный анализ состояния ликвидности предприятия. Журнал: «Финансовый вестник: финансы, налоги, страхование, бухгалтерский учет» № 4, апрель 2011.

3. Michael Owens, The advantages of ratio analysis. Журнал: «Elsevier», June 2010

4. Jeff Jewell, Why financial ratios are useful? Журнал: Lipscomb University, 23.03.2017.

5. Proff. Cram, Ratio analysis. Журнал «Buisness economics», September 2018. 